\title{
SMART PRODUCT DESIGN AND PRODUCTION CONTROL FOR EFFECTIVE MASS CUSTOMIZATION IN THE INDUSTRY 4.0 CONCEPT
}

\author{
Przemysław Zawadzki, Krzysztof Żywicki \\ Poznan University of Technology, Chair of Management and Production Engineering, Poland \\ Corresponding author: \\ Przemystaw Zawadzki \\ Poznan University of Technology \\ Chair of Management and Production Engineering \\ Piotrowo 3, 60-965 Poznań, Poland \\ phone: $(+48) 616652708$ \\ e-mail: przemyslaw.zawadzki@put.poznan.pl
}

Received: 5 June 2016

Accepted: 7 September 2016

\begin{abstract}
The paper presents a general concept of smart design and production control as key elements for efficient operation of a smart factory. The authors present various techniques that aid the design process of individualized products and organization of their production in the context of realization of the mass customization strategy, which allows a shortened time of development for a new product. Particular attention was paid to integration of additive manufacturing technologies and virtual reality techniques, which are a base of the so-called hybrid prototyping.
\end{abstract}

KEYWORDS

Industry 4.0, mass customization, virtual prototyping, additive manufacturing technologies, knowledge-based systems.

\section{Introduction}

Fulfilling individual requirements of clients is becoming a more important factor in determining the competitiveness of an enterprise [1]. In the near future, companies that strive at realization of a concept of a smart factory will become leaders in this field. In a smart factory, the role of a human is greatly limited, with a focus on automatic gathering and processing of data about processes and production machines [2]. Use of modern information technologies, such as the cyber-physical systems or the internet of things, and the processing of vast amounts of data (Big Data), is a foundation of a concept known as Industry $4.0[3,4]$. Industry 4.0 assumes preparation of a computerized, intelligent manufacturing environment, guaranteeing flexibility and high efficiency of production, integration of different activities and effective communication between a client and a producer, as well as between the producer and suppliers. The concept of Industry 4.0 joins techno- logical achievements from recent years with a vision of future intelligent and automated production systems, in which a real world is connected with a virtual one, ensuring more efficient use of available information [5].

In practice, achieving full capability to organize production in conformity with the Industry 4.0 concept, especially by the SMEs, will surely require 1020 years. However, it can be assumed that the smart factories of the future will be autonomous units, able to plan, organize and even control the production themselves. This is why the idea of Industry $4.0 \mathrm{can}$ be key in realizing assumptions of a strategy known as mass customization (MC), which is focused on fulfilling individual client requirements by production companies [6].

Although the MC concept has been known for years, its effective implementation is still an immense challenge [7-9] because it requires the manufacturers to be ready to change variants of products and their manufacturing processes efficiently, as well as to se- 


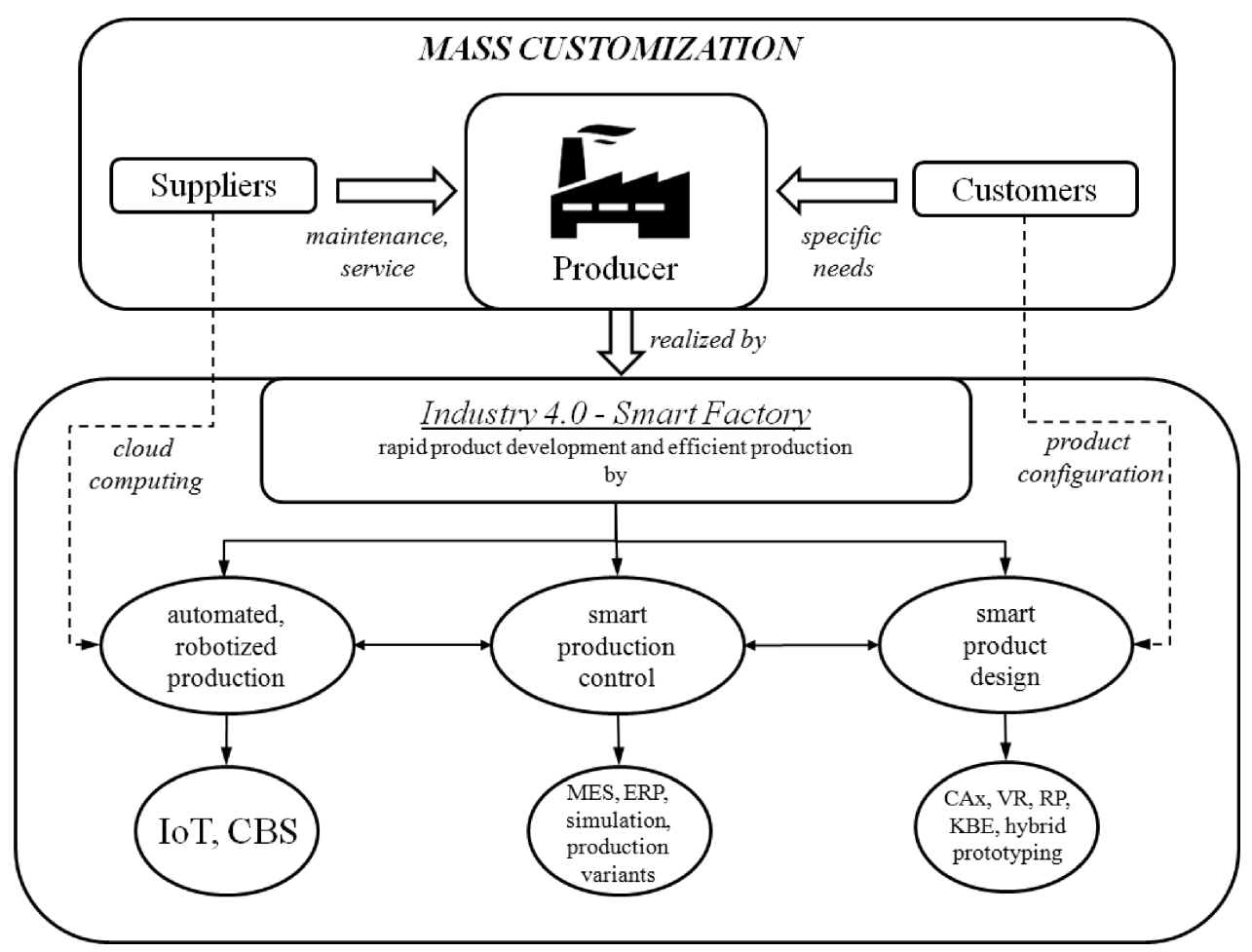

Fig. 1. Realization of the MC strategy by an intelligent factory.

lect the best solutions according to different criteria (economics, quality). Therefore, building smart factories cannot be limited only to new technical solutions in the area of manufacturing itself. Their functioning will have to be based upon knowledge based on the experience of the whole company (on the basis of earlier production cases), analysis and exchange of a large amount of current data (requirements versus production capabilities), as well as rapid testing of many alternative solutions through advanced simulations. Without perfection of the product design processes and preparation and control of their manufacturing, efficient achievement of the MC assumptions and maintaining their positive results will not be possible (Fig. 1).

Achieving goals defined this way requires taking a risk with investment in new tools, from the area of the advanced CAx systems, virtual reality technologies or additive manufacturing processes, aiding both virtual and physical preparation of a new product design. Digital models of products and production processes, enriched with a properly prepared knowledge base, are essential elements of intelligent IT systems, integrating configuration of a product by a client on the one side and automatic preparation of an appropriate product design and its manufacturing process in a company on the other side.

The aim of this paper is to present concepts of smart product design and smart production control as necessary elements of a smart factory able to realize the MC strategy in an efficient way.

\section{Challenges of mass customization}

Mass customization is defined through a certain sort of contradiction. By assumption, it should join advantages of single piece production (individually and precisely) and mass production (quickly and inexpensively). Its implementation is highly attractive from a client's point of view, but it is a significant hindrance for a company and brings a risk of failure, especially as a result of increase of design and manufacturing costs. In contrast to mass production, which is large amounts of repeatable (often identical) products, MC allows fulfilment of the expectations of every client by adjusting a product to the client's needs.

The MC strategy becomes a competitive strategy under the condition that the company is able to quickly respond to expectations and requirements of its customers. In other words, it is able to join the MC strategy with another strategy known in literature as Quick Response [10]. This connection is possible if a company has a flexible manufacturing system and a possibility of rapid design (in terms of duration), as well as implementation of new products and processes of their manufacturing. 
A measure of flexibility of a manufacturing system is its capability to perform different tasks and the "speed" at which it can be prepared for a new task. Rapid design of a product means automated design, while rapid implementation of a process is related to use of rapid manufacturing techniques. The scheme in Fig. 2 shows that if any of these factors - flexibility or automation - is not sufficient, it is difficult to realize the Quick Response goal. In the case of an insufficient flexibility, products designed in a short time must still wait for their turn. If, on the other hand, the design is failing (meaning that it lasts too long), the manufacturing system is then not fully loaded. In both cases the customer lead time is prolonged and can be unacceptable.

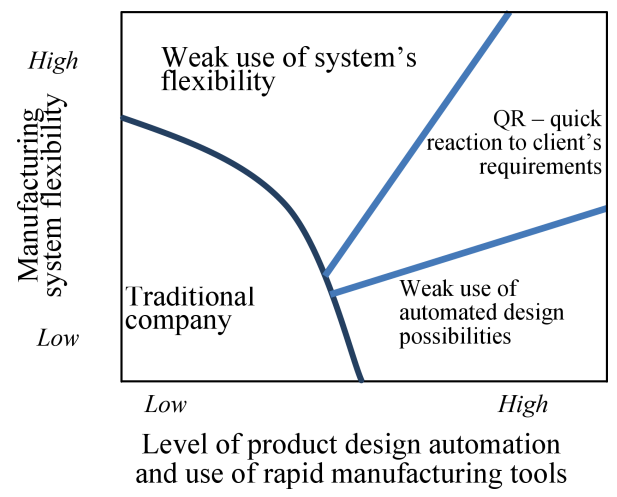

Fig. 2. The Quick Response strategy.

Effectiveness of the MC strategy is also highly dependent on the kind of influence on a product shape that is in the hands of its recipient, because the range of configuration of a designed product is still decided by its producer. The highest level of customization, known as the collaboration customization, is achieved when a recipient is assumed to be engaged during design and manufacturing of a product variant [7]. To this end, special types of software applications are used more and more frequently product configurators. They allow clients to precisely define their requirements themselves. The configurators have found application in many branches, e.g., automotive, clothing, furniture or civil engineering, and aid the sales process and improve communication between the producer and the recipient. Dynamic development of web-based applications in recent years has forced companies to share variant product configurators with their clients through the Internet [11]. In a typical configuration process, there is a choice inside a limited set of variable options and their values, while some solutions allow a recipient to define them freely, further increasing the customization level. A number of product variants possible to obtain is, in such a case, theoretically unlimited. This increases the attractiveness of a company's offerings on the one hand but is a huge organizational challenge on the other hand.

Development of configuration applications more and more often goes beyond the sales field, allowing automation of information flow inside a manufacturing company. A smart factory, fulfilling aims of $\mathrm{MC}$, must be able to process these configuration data effectively. Even today, in the design area, there is a tendency to develop technical documentation for a new product variant automatically, without participation of a design engineer [12, 13]. Advanced CAx systems are used for that purpose, allowing enrichment of geometrical CAD models with a formal description of engineering knowledge. Digital and intelligent product models created this way are a base of so-called Knowledge Based Engineering (KBE) systems [14].

\section{Smart product design}

Smart design refers to design that is easy, quick, and - most importantly - correct in the first iteration. KBE-based design fulfills these assumptions. Solutions of KBE class contain expert knowledge about how, when and what needs to be done, identified, gathered and further processed by a computer system, allowing its easier application in new projects. A formal description of rules applied by the design engineers helps process standardization and allows automation of repeatable tasks in the design process [15-17]. Application of solutions based on knowledge description at an early stage of product development also decreases costs of the whole project and facilitates selection of the best solution [18]. Building and implementation of a KBE system in a design process of variant products can be a way in which a company can realize assumptions of the MC strategy $[15,19]$.

The most important reason to consider building a KBE system is, above all, the possibility of rationalization of the design process. It is estimated that approximately. $80 \%$ of design time is spent on routine tasks [20,21]. Acceleration can significantly help optimize the whole product lifecycle and cause certain savings. This is why a basic advantage of using $\mathrm{KBE}$ solutions is the possibility of automation of repeatable tasks [22], simultaneously influencing capabilities of realization of creative work [17].

Problems of gathering, representation and application of knowledge in KBE-class computer systems are dealt with by the knowledge engineering, which is known as a branch related to creation of knowledge databases and use of semantic technologies to process knowledge through computer systems, including: 
- identification of knowledge sources,

- acquisition (obtaining) of knowledge,

- representation of knowledge,

- analysis of identified knowledge,

- creation of bases and repositories of knowledge,

- searching, accessing and sharing knowledge.

Effective application of knowledge in a design process requires its proper acquisition and correct recording in a knowledge database. These apparently obvious activities actually present a number of huge challenges for engineers, causing $80 \%$ of solutions of this type to be prepared in an immediate manner [15]. This happens in spite of available standards of building of KBE systems, which have been present for years and are aimed at ordering knowledge processing procedures. Examples of these standards are methodologies such as MOKA, KNOMAD or KADM [21-23].

An example that presents how to obtain smart design by use of $\mathrm{KBE}$ is a system for automation of couplings used in sanitary installations [12]. The authors of this solution assumed integration of configuration and product variant design processes in a way to automatically generate technical documentation of a product and its production tools in a CAD system (Fig. 3). Realizing requirements of MC, regarding participation of a recipient in a design process, a dedicated user interface was created, available from the WWW browser level. Moreover, the developed system partially comprises automation of manufacturing process preparation of a new product variant thanks to specially developed generative CAD models and CAM machining process templates. A strong advantage of the solution is the data flow in a project - it allows preparation of the whole technical documentation without participation of qualified engineering staff. Therefore, the system of smart design

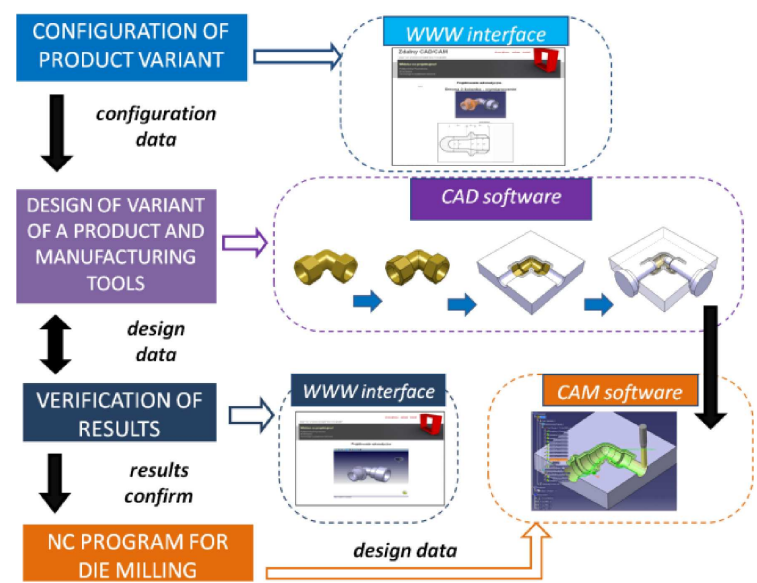

Fig. 3. Architecture of a system for design of installation couplings [12]. on the basis of KBE can be a foundation for all activities in a smart factory. e processes of sales, design and manufacturing preparation (Fig. 4) [24, 25].

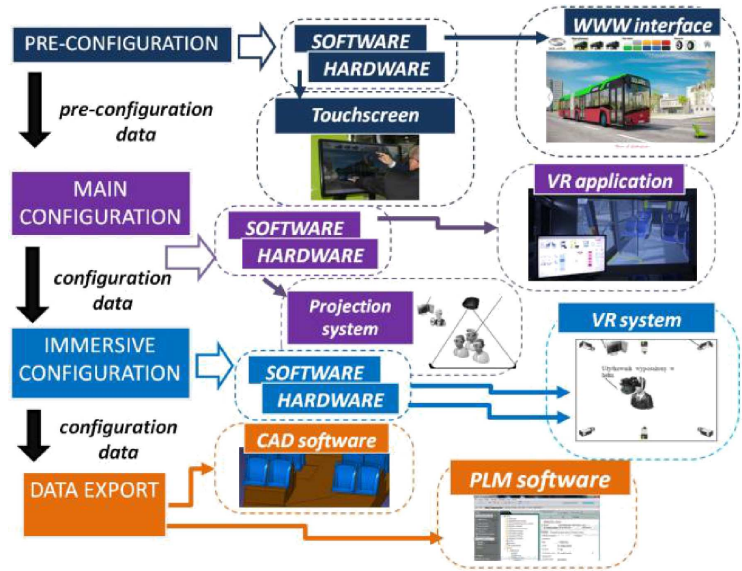

Fig. 4. Architecture of a city bus configuration system [24].

Not only KBE can decide about effectiveness of smart design. Shortening the time of building a prototype of a product and its verification is a domain in which virtual reality (VR) can be applied. Virtual reality systems are increasingly used in engineering design. An example of such an approach is an interactive system of a city bus configuration - a software application that aids th

Virtual Reality is a basis of smart design here, as it facilitates verification of recipients' own ideas and comparison of different vehicle variants (selection from a few hundred options). An integrated computer system was developed, in which the configuration can be realized remotely - through the Internet - or locally, at the company's location, using VR-based visualization. The configuration data was integrated with a PLM system present in the company and partially with a CAD system. In the latter, on the basis of configuration results, an initial model of seat arrangement in a bus is built automatically and can be used for further work by the design engineers.

\section{Hybrid prototyping}

A good design is not made by accident. Features that a product receive during the manufacturing process, even if they fulfill technical and functional requirements, are not worth much if they do not respond to a client's expectations. Verification of a virtual prototype is often insufficient and a physical prototype must be prepared. Building a prototype by use of traditional manufacturing technologies requires time and significant investments. However, if this stage cannot be omitted in a creative process, 
other methods and tools should be used in the smart design approach.

A promising solution to this problem seems to be integration of rapid prototyping techniques with VR. Both these technologies are sometimes classified as belonging to the so-called time-compression technologies [26]. In the case of rapid prototyping techniques, a prototype is produced directly from a digital model of a product and the time of obtaining the prototype is usually much shorter than by use of conventional manufacturing technologies [27]. In the case of VR, the time shortening effect is achieved mostly by implementation of so-called virtual prototyping, meaning creating a digital prototype highly similar in some aspects to a real product, and then performing necessary tests and studies on it, without the necessity of building a physical prototype [28, 29].

In industry, awareness of possible applications of both techniques is still low and if they are used, it happens sequentially and separately (Fig. 5, paths A, $\mathrm{B}$ and $\mathrm{C}$ ) - a virtual prototype has no connection with a physical one. A new approach to this issue is known as hybrid prototyping (Fig. 5 - path D). It assumes connection between models and prototypes obtained using rapid prototyping techniques with interactive virtual prototypes [26]. Physical models manufactured by the RP techniques (usually in layered manner) are used in connection with advanced VR devices (such as haptic manipulators or tracking systems) as tools for interaction in a virtual environment. This helps to increase realism of VR simulations and opens entirely new areas of simulation, especially in an ergonomic aspect.

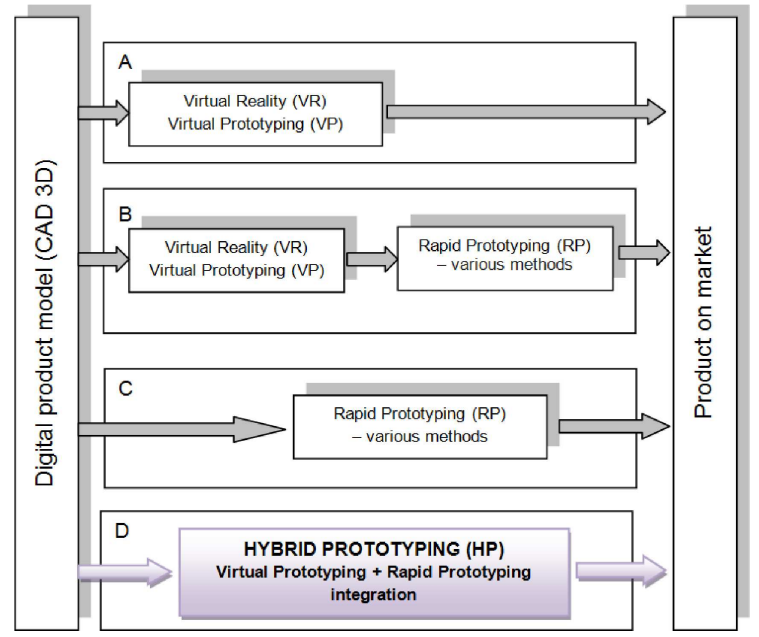

Fig. 5. Time-compression technologies in manufacturing preparation [26].

The most important component of each hybrid prototype is always a VR application. A "VR application" needs to be understood as a closed whole in programming terms, which contains virtual models of objects placed in an appropriate environment with interaction and immersion ensured for the user $[30,31]$. The two basic VR application types are: single object oriented (usually an object is a virtual model of a specific product) and scene oriented. The most popular engineering VR applications nowadays are, among others, virtual simulation of operation, service, assembly and disassembly [32], virtual workplaces [27, 31] or product configurators [24, 33]. Depending on the lifecycle phase of a product, at which a VR application of a specific type is created, it can be used to test functions of a product, train the staff or visualize the product for sales and marketing purposes [26].

Hybrid prototyping, thanks to integration of physical models with interactive, immersive VR applications, has wide perspectives of development. Because of a plethora of potential applications, especially in production engineering, but also, e.g., in biomedical engineering [34], which allows the assumption that this way of application of rapid and virtual prototyping will soon be widespread. That is because in this approach, advantages of traditional, tangible physical prototypes are joined with rich possibilities of computer-generated visualizations and intuitive interaction ensured by advanced VR systems, which in consequence allows a high realism of simulations to be obtained. A disadvantage of hybrid prototyping is the significant cost of development of these solutions, which limits the scale of commercial applications.

\section{Smart production control}

Realization of MC strategy introduces a number of huge challenges to processes of production control. They have a direct influence on effectiveness of use of available resources and of obtaining aims regarding efficiency and costs of production. Fulfilling variable requirements of clients requires systematic solutions in the scope of production scheduling, material flow monitoring and analysis and decision making. In this context, smart production will be possible if assumed control methods will enable dynamic reaction on external and internal factors that have an influence on the functioning of a production system. This is why these methods must take specificity of a production system and manufacturing processes into consideration $[35,36]$.

From the viewpoint of smart production, the most important aim is synchronization of material flow in a production system. Starting from coordination of material supplies, through the flow of production between subsequent resources, and end- 
ing with preparation of a supply and shipping products to a client. Design and process knowledge of manufactured products is a base for decision making here. Considering the diversity of client requirements, applied methods of scheduling must take into account a possibility of producing products using various manufacturing resources. It allows quick reaction as a result of appearance of new orders or factors disabling their use. This is why it is increasingly important to strictly integrate scheduling with the production planning processes.

As a result of so many factors, which need to be taken into consideration during preparation of a production schedule, it is a necessity to implement methods that allow introduction of dynamic changes (fast dynamic scheduling) [37]. Additionally, a scheduling process should be realized on the basis of material flow variants that are possible to realize. It allows selection of the most effective material flow on the basis of given criteria, e.g. use of production resources or the shortest realization time (Fig. 6).

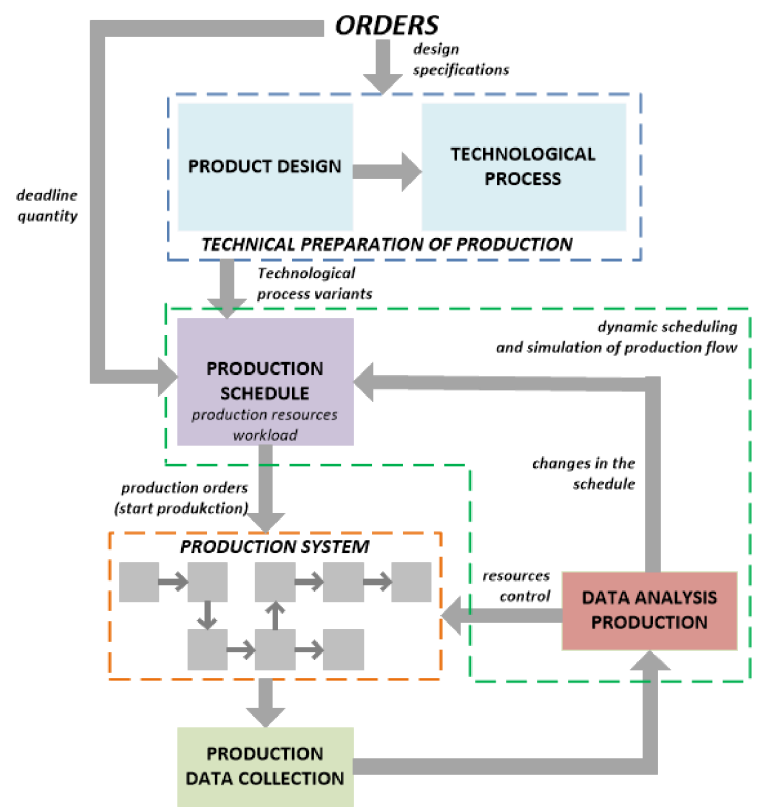

Fig. 6. Process of control of production flow.

An effective production control can be realized only in the case of having the necessary knowledge regarding phenomena and interaction in the production flow. A solution in this area is to introduce the internet of things concept into the production control processes, along with augmented reality.

The internet of things is a concept in which identifiable objects can directly or indirectly gather, analyze and exchange information using a computer network. This solution allows data regarding the material flow and operation of machines and manufacturing devices to be obtained. On that basis, with use of an- alytical models, it is possible to forecast negative results of occurrence of a specific event, such as a malfunction, error in the work of a machine or exceeding standard time of performing a production task. Thanks to this, it is possible to consider these factors in the development of a production schedule, but it also makes it possible to plan the maintenance work or to order spare parts in a more effective manner.

There is no doubt that the internet of things allows correct decisions regarding machine operation to be made or material to flow faster; nevertheless, the final decisions are always made by a human [38].

Existing solutions in the area of automated production and industrial automatics allow use of the internet of things concept for strict information integration of manufacturing devices in the area of cyber-physical systems. Through controllers and sensors, these systems monitor and analyze data from the production processes, while the communication devices allow mutual interaction between production resources in real time. As such, a cyber-physical production system is created, characterized by autonomy of decision making with no human engagement $[39,40]$.

Use of solutions to join real objects or production processes with real-time generated digital objects increases the speed at which information is obtained. They are solutions out of the AR area, allowing online information sharing. As such, it becomes possible to make rational decisions at the moment of occurrence of problems or deviations during realization of production orders.

An idea of smart production, when fully realized, will also allow realization of the $\mathrm{MC}$ concept, but only under a condition of implementation of solutions that allow decisions to be made based on reason as a result of dynamic changes in a production system. Only then it is possible to achieve the required flexibility of a production system on an organizational level and not only on a technical level.

\section{Conclusions}

It is the opinion of the authors' that smart design and production control are necessary elements of a smart factory of the future that is able to realize the MC strategy. Only then will it be fully possible to utilize the manufacturing potential of a company with modern technical resources and in compliance with the Industry 4.0 concept.

In order to fulfill the elementary idea of the MC concept, which is supporting each client with individualized products, application of automated and knowledge-based design systems is invaluable. The 
authors believe that further development of the KBE systems should focus on preparation of standards of gathering and processing of knowledge, especially in the field of hybrid design. Generally, there are no tools that allow selection of proper VR and RP techniques for a given process, as well as evaluation of automation potential of a given variant product (regarding current market needs and necessary workload). In the authors' experience, without conducting such analyses, building smart design solutions may not bring expected benefits, the lifecycle of such systems will be short, and design engineers will return to traditional design methods after a certain time.

Diversity of variants of products is also a challenge in terms of scheduling and production control, with assumption of effective utilization of available production resources and synchronization of material flow in a production system. Available solutions - methods or systems aiding the production control processes - must be capable of processing large amounts of data, which will be subjected to analysis, allowing rational decisions related to the material flow to be made. In such a case, it is most important to obtain current information from the environment of a production system (client requirements) and information regarding availability and functioning of a production system. Realization of such tasks is facilitated, among other things, by the internet of things (concerning functioning of a production system) and efficient exchange of data between computer systems, related, for example, to design or process planning of manufacturing products and to coordination of the material supplies and cooperation.

\section{References}

[1] Hamrol A., Strategie i praktyki sprawnego działania [in Polish], Wydawnictwo Naukowe PWN, Warszawa 2015 .

[2] Brettel M., Friederichsen N., Keller M., Rosenberg M., How virtualization, decentralization and network building change the manufacturing landscape: an Industry 4.0 perspective, International Journal of Mechanical, Aerospace, Industrial, Mechatronic and Manufacturing Engineering, 8, 1, 2014.

[3] Ivanov D., Dolgiu A., Sokolov B., Werner F., Ivanova M., A dynamic model and an algorithm for shortterm supply chain scheduling in the smart factory Industry 4.0, International Journal of Production Research, 54, 2, 386-402, 2016.

[4] Lee J., Bagheri B., Kao H.A., A cyber-physical systems architecture for Industry 4.0-based manufacturing systems, Manufacturing Letters, 3, 18-23, 2015 .
[5] Gorecky D., Schmitt M., Loskyll M., Zuhlke D., Human - machine - interaction in the Industry 4.0 ERA, Industrial Informatics (INDIN), 12th IEEE International Conference, 289-294, 2014.

[6] Shrouf F., Ordieres J., Miragliotta G., Smart factories in Industry 4.0: a review of the concept and of energy management approached in production based on the internet of things paradigm, Industrial Engineering and Engineering Management (IEEM), IEEE International Conference on. IEEE, 2014.

[7] Gilmore J.H, Pine II B.J., The four faces customization, Harvard Business Review, January-February pp. 21-30, 1997.

[8] Fogliatto F.S., da Silveira G.J., Borenstein D., The mass customization decade: An updated review of the literature, International Journal of Production Economics, 138, 1, 14-25, 2012.

[9] Salvador F., de Holan P.M., Piller F., Cracking the code of mass customization, MIT Sloan Management Review, 50, 3, 71-78, 2009.

[10] Ko E., Kincade D., Brown J.R., Impact of business type upon the adoption of quick response technologies International Journal of Operations \& Production Management, 20.9, 1093-1111, 2000.

[11] Grosso C., Trentin A., Forza C., Towards an understanding of how the capabilities deployed by a Webbased sales configurator can increase the benefits of possessing a mass-customized product, 16th International Configuration Workshop, 21, 81, 2014.

[12] Gorski F., Hamrol A., Kowalski M., Paszkiewicz R., Zawadzki P., An automatic system for 3D models and technology process design, Transactions of FAMENA, 35, 2, 2011.

[13] Lin B.T., Hsu S.H., Automated design system for drawing dies, Expert Systems with Applications, 34, 1586-1598, 2008.

[14] Chapman C.B., Pinfold M., Design engineering a need to rethink the solution using knowledge based engineering, Knoledge-Based System, 12, 257-267, 1999.

[15] Verhagen W.J.C., Bermell-Garcia P., Van Dijk R.E.C., Curran R., A critical review of KnowledgeBased Engineering: An identification of research challenges, Advanced Engineering Informatics, 26, 1, 5-15, 2012.

[16] Choi J.W., Kelly D., Raju J., Reidsema C., Knowledge-based engineering system to estimate manufacturing cost for composite structures, Journal of Aircraft, 42, 6, 1396-1402, 2005.

[17] Van der Laan A.H., Knowledge based engineering support for aircraft component design, Design of Aircraft and Rotorcraft, Faculty of Aerospace Engineering, Delft University of Technology, Delft, p. 254,2008 . 
[18] Tarkian M., Design reuse and automation, Printed in Sweden by LiU-Tryck Linköping, 2009.

[19] Elgh F., Cederfeldt M., Documentation and management of product knowledge in a system for automated variant design: a case study, New World Situation: New Directions in Concurrent Engineering, Springer, London, pp. 237-245, 2010.

[20] Pokojski J., Inteligentne wspomaganie procesu integracji środowiska do komputerowo wspomaganego projektowania maszyn [in Polish], WNT, Warszawa, 2000 .

[21] Stokes M., Managing engineering knowledge; MOKA: methodology for knowledge based engineering applications, Professional Engineering Publishing, London, 2001.

[22] Skarka W., Metodologia procesu projektowokonstrukcyjnego opartego na wiedzy [in Polish], Wydawnictwo Politechniki Slaskiej, Gliwice, 2007.

[23] Curran R., Verhagen W.J.C., Van Tooren M.J.L., Van der Laan A.H., A multidisciplinary implementation methodology for knowledge based engineering: KNOMAD, Expert Systems with Applications, 37, 11, 7336-7350, 2010.

[24] Gorski F., Bun P., Wichanirek R., Zawadzki P., Hamrol A., Immersive city bus configuration system for marketing and sales education, Procedia Computer Science, 75, 137-146, 2015.

[25] Gorski F., Bun P., Wichniarek R., Zawadzki P., Hamrol A., Design and implementation of a complex virtual reality system for product design with active participation of end user, Advances in $\mathrm{Hu}-$ man Factors, Software and Systems Engineering, B. Amaba [Ed.], Advances in Intelligent Systems and Computing 492, p. 31-43, Springer, 2016.

[26] Gorski F., Hamrol A., Grajewski D., Zawadzki P., Integracja technik wirtualnej rzeczywistości $i$ wytwarzania przyrostowego - hybrydowe podejście do rozwoju wyrobu [in Polish], Mechanik, 3/2013, $4 / 2013$.

[27] Gorski F., Wichniarek R., Kuczko W., Zawadzki P. Bun P., Strength of ABS parts produced by Fused Deposition Modelling technology - a critical orientation problem, Adv. Sci. Technol. Res. J., 9/26, 12 19, 2015.

[28] Grajewski D., Gorski F., Zawadzki P., Hamrol A., Application of Virtual Reality Techniques In Design Of Ergonomic Manufacturing Workplaces, International Conference on Virtual and Augmented Reality in Education Volume, 25, 289-301, 2013.

[29] Pandilov Z., Milecki A., Nowak A., Gorski F., Grajewski D., Ciglar D., Klaić M., Mulc T., Virtual Modelling and simulation of a CNC machine feed drive system, Transactions of FAMENA, 39, 4, January 2016.
[30] Bun P., Gorski F., Wichniarek R., Kuczko W., Hamrol A., Zawadzki P., Application of professional and low-cost head mounted devices in immersive educational application, Procedia Computer Science, 75, 173-181, 2015.

[31] Grajewski D., Gorski F., Hamrol A., Zawadzki P., Immersive and haptic educational simulations of assembly workplace conditions, Procedia Computer Science, 75, 359-368, 2015.

[32] Grajewski D., Diakun J., Wichniarek R., Dostatni E., Buń P., Górski F., Karwasz A., Improving the skills and knowledge of future designers in the field of ecodesign using virtual reality technologies, International Conference Virtual and Augmented Reality in Education, Procedia Computer Science, 75, 348-358, ISSN 1877-0509, 2015.

[33] Maleshkov S., Katicic J., Stojanova P., Bachvarov A.G., Design-by-the-Customer through Virtual Reality, Advanced Research in Virtual and Rapid Prototyping, Proceedings of VR@P4,Leiria, Portugal, 2009.

[34] Buń P., Górski F., Wichniarek R., Kuczko W., Zawadzki P., Immersive educational simulation of medical ultrasound examination, Procedia Computer Science, 75, 186-194, 2015.

[35] Trojanowska J., Żywicki K., Pająk E., Influence of selected methods of production flow control on environment, Information Technologies in Environmental Engineering, 3, 695-705, 2011.

[36] Trojanowska J., Żywicki K., Varela M.L.R., Machado J., Improving production flexibility in an industrial company by shortening changeover time: a triple helix collaborative project, multiple helix ecosystems for sustainable competitiveness, Springer International Publishing, pp. 133-146, 2016.

[37] Piłacińska M., Leśniak K., Kujawińska A., Żywicki K., The data model of production flow and quality control system [in Polish], Studia Informatica, 30, 2B, 109-126, 1642-0489, 2009

[38] Colombo A., Bangemann T., Karnouskos S., Delsing J., Stluka P., Harrison R., Jammes F., Lastra J.L., Industrial cloud-based cyber-physical systems: the IMC-AESOP approach, New York: Springer, 2014.

[39] Seitza K.F., Nyhuisa P., Cyber-physical production systems combined with logistic models - a learning factory concept for an improved production planning and control, The 5th Conference on Learning Factories 2015, Procedia CIRP 32, pp. 92-97, 2015.

[40] Veigt M., Labbe D., Hribernik K.A., Scholz-Reiter B., Entwicklung eines Cyber-Physischen Logistiksystems, Industrie Management, 1, 15-18, 2013. 